\title{
CORRESPONDENCE
}

\section{Big projects would be shooting in the dark without team effort}

In your Column (Nature 466, 919; 2010), the story about me, Congressman Dana

Rohrabacher and my pistols is not quite accurate. Neither did the Manhattan Project leave scientists with the belief that they could run their own projects by themselves.

The subject of guns came up over dinner with Rohrabacher at Stanford University (not at my home) when I was director of the Stanford Linear Accelerator Center and he was chairman of the energy and environment subcommittee of the House of Representatives science committee. I had been a target shooter, having started as a graduate student member of the faculty pistol team at the Massachusetts Institute of Technology (times were different in 1953). Rohrabacher was indeed surprised to learn that I owned a small collection of guns and used them in competition; relations between us improved after that.

You are wrong in saying that scientists preferred to run major projects themselves after the Second World War. That was not the training I received. Although scientists were at the top, engineers, managers and business people were all regarded as critically important team members. Compromises have to be made in constructing all big projects, and the Oppenheimers and Panofskys of the time correctly believed that it was the job of the scientist to choose where to compromise, with minimal effect on capabilities, and that a scientist should have the final word. It was true then and is true now: had the old tradition still been in force, perhaps the international fusion project ITER would have fared better.
2575 Sand Hill Road, Palo Alto, California 94025, USA

e-mail: brichter@slac.stanford.edu

\section{Urban ecosystems research joins mainstream ecology}

Your call for more investigation into the ecology of urban

habitats (see Nature doi:10.1038/ news.2010.359; 2010) is already being answered.

In 1997, the US National Science Foundation's Long-Term Ecological Research programme created urban research sites in Baltimore, Maryland, and in Phoenix, Arizona. And last year the foundation funded the Urban Long-Term Research Area Exploratory Awards with the US Forest Service to expand knowledge of urban natural resources and human interactions. These programmes attest to a coordinated and productive effort to incorporate urban research into mainstream ecology.

Publications on this topic have mushroomed over the past two years: they include specialist journals (Urban Ecology, Urban Ecosystems); a 'Cities' special in Science $(319,739-775 ; 2008)$ and books such as Urban Herpetology, Urban Carnivores and Advances in Urban Ecology.

Membership of the Urban Ecosystem Ecology section of the Ecological Society of America is growing fast - it is now the twelfth largest of 19 sections. There were 202 urban-related items presented at the society's annual meeting last month, compared with just one in 1991.

Although the number of published urban studies is still small, it is rapidly increasing. Only $0.4 \%$ of papers in nine leading ecology journals in 1993-98 dealt with cities or urban species (J. Collins et al. Am. Sci. 88, 416-425; 2000), compared with $2.5 \%$ of papers in 10 top ecology journals over the past 5 years (see go.nature.com/Lj7YAa).

Urban environments were not even recognized as ecosystems until recently. To understand the impact of human activity, we need to compare the entire range from pristine to altered systems. Many ecologists are already up to the challenge.

Paul Mayer US Environmental Protection Agency, Ada, Oklahoma 74820, USA e-mail:mayer.paul@epa.gov The full list of signatories to this Correspondence is available online at http://dx.doi.org/10.1038/467153b

\section{A call for action to curb invasive species in South America}

South America's exceptional biodiversity is in danger of being overwhelmed by invading species. The continent urgently needs to muster a common strategy of regional action against this threat.

Of all mammal invasions worldwide, more than $18 \%$ are in South America, and twothirds of these are successfully established. In addition, 41 of the 100 most invasive alien species from all taxa are established in the region. The continent's indigenous plant life is a rich source of food and medicines, and helps to regulate weather cycles, but invasive species command little attention from scholars or governments.

Every South American country ratified the 1993 Convention on Biological Diversity, which aims to prevent, control and eradicate alien species. Yet even basic national reports on alien species are still not forthcoming.

South Americans need to be more aware of the problem and of the value of their own native species and culture. As in Europe, we need to improve rulings on tourism and on the transport of pets, seeds and aquarium and garden species. Countries should share regional and national databases of alien species and devise common policies for managing them. Karina Speziale, Sergio Lambertucci
Laboratorio Ecotono, INIBIOMA (Comahue National University/ CONICET), Bariloche, Argentina e-mail: kspeziale@crub.uncoma.edu.ar

\section{Chinese journal finds $31 \%$ of submissions plagiarized}

Since October 2008, we have detected unoriginal material in a staggering $31 \%$ of papers submitted to the Journal of Zhejiang University-Science (692 of 2,233 submissions). The publication, designated as a key academic journal by the National Natural Science Foundation of China, was the first in China to sign up for CrossRef's plagiarismscreening service CrossCheck (Nature 466, 167; 2010).

We are therefore campaigning for authors, researchers and editors to be on the alert for plagiarism and to work against cultural misunderstandings. In ancient China, for example, students were typically encouraged to copy the words of their masters.

To this end, we have given lectures and written three papers (including Y. H. Zhang Learn. Publ. 23, 9-14; 2010) that have been widely publicized in China's media (see go.nature.com/dPey7X; in (hinese) and reported in CrossRef's quarterly online news magazine (see go.nature.com/ icUwvh). Our website displays the CrossCheck logo to remind authors of their responsibilities.

Other Chinese journals are also policing plagiarism, using software launched in 2008 by China's Academic Journals Electronic Publishing House and Tongfang Knowledge Network Technology in Beijing.

Yuehong Zhang Journal of Zhejiang University-Science, 38 Zheda Road, Hangzhou 310027, China e-mail:jzus@zju.edu.cn

Contributions to Correspondence may be submitted to correspondence@nature.com; see go.nature.com/cMCHno. 